Article

\title{
Early History, Mealtime Environment, and Parental Views on Mealtime and Eating Behaviors among Children with ASD in Florida
}

\author{
Heewon L. Gray ${ }^{1, *(\mathbb{D}}$, Sweta Sinha ${ }^{1}$, Acadia W. Buro ${ }^{1}{ }^{\mathbb{D}}$, Chantell Robinson $^{1}$, Karen Berkman ${ }^{2}$, \\ Heather Agazzi ${ }^{3}$ and Emily Shaffer-Hudkins ${ }^{3}$ \\ 1 College of Public Health, University of South Florida, 13201 Bruce B Downs Blvd, Tampa, FL 33612, USA; \\ swetasinha@health.usf.edu (S.S.); acadia@health.usf.edu (A.W.B.); cnr@health.usf.edu (C.R.) \\ 2 Center for Autism \& Related Disabilities and Department of Child and Family Studies, University of South \\ Florida, 13301 Bruce B Downs Blvd, Tampa, FL 33612, USA; kberkman@usf.edu \\ 3 Department of Pediatrics, University of South Florida, 13101 Bruce B Downs Blvd, Tampa, FL 33612, USA; \\ hcurtiss@health.usf.edu (H.A.); eshaffer@health.usf.edu (E.S.-H.) \\ * Correspondence: hlgray@health.usf.edu; Tel.: +1-(813)-974-9881
}

Received: 8 August 2018; Accepted: 22 November 2018; Published: 2 December 2018

\begin{abstract}
This study was a cross-sectional study to examine problematic mealtime behaviors among children with autism spectrum disorder (ASD) in Florida. Forty-one parents completed a 48-item survey. The mean age of their children was 8.1 years and $73 \%$ were male. The data were divided and compared by age group: Ages 2-6, 7-11, and 12-17. Data from the 3- to 6-year-old children were extracted and compared with the references from Provost et al. (2010). There were age differences in eating difficulties at home $(p=0.013)$, fast food restaurants $(p=0.005)$, and at regular restaurants $(p=0.016)$. The total mealtime behavior score was significantly higher in early childhood $(p<0.001)$ and mid-childhood $(p=0.005)$ than adolescents. More parents of ages 3-6 with ASD reported difficulties with breastfeeding ( $p<0.01)$; concerns about eating $(p<0.001)$; difficulties related to mealtime locations $(p<0.05)$, craving certain food $(p<0.05)$, and being picky eaters $(p<0.01)$ compared to typically developing children. The total mealtime behavior score was significantly higher in children with ASD than typically developing children $(p<0.001)$. The results indicate that early childhood interventions are warranted and further research in adolescents is needed.
\end{abstract}

Keywords: autism spectrum disorder; mealtime behavior; children; diet; feeding behavior

\section{Introduction}

Children with autism spectrum disorder (ASD) frequently exhibit feeding difficulties and problematic mealtime behaviors [1-3] and consume fewer types of foods compared to typically developing children [4-6]. Food selectivity, or consuming a narrow variety of foods [7], has been associated with other problematic, ritualistic behaviors, which may contribute to inadequate nutrient intake [3,8-10]. A meta-analysis and review study indicated that children with ASD experience about five times more feeding problems and significantly lower intake of calcium and protein compared to a typically developing comparison group [2]. In addition, selective eating has been associated with preference for energy-dense foods such as sweetened beverages and snack foods as well as with inadequate consumption of nutrient dense foods such as fruit, vegetables, lean protein, and foods high in fiber [11]. Such imbalanced eating behaviors may contribute to the high prevalence of obesity in children with ASD. Children with ASD are up to $40 \%$ more likely to be obese than typically developing children [12-14]. In addition, adults with ASD are at high risk for developing hyperlipidemia, diabetes, coronary heart disease, and cancer [15]. Taken together, addressing problematic mealtime behaviors 
that may contribute to developing unhealthy dietary habits early in childhood is critical. Parents of children with ASD have also reported concerns regarding their children's mealtime behaviors and the potential impact of these behaviors on their children's nutritional status and well-being $[9,16]$. Furthermore, it has been reported that selective eating and problematic mealtime behaviors persist through the adolescent years $[17,18]$; however, whether or not there are any age differences in these behaviors has not been further examined. To better understand any demographic or regional differences in feeding or mealtime behaviors among children with ASD, further studies are needed with samples from diverse demographic backgrounds and regions.

The purpose of this study was to examine mealtime behaviors in children who are clinically diagnosed with ASD, specifically among children who reside in Florida. As some feeding difficulties can be recognized at a very early age, we selected a questionnaire that includes questions on children's early feeding history. Provost et al. (2010) developed and validated a 48-item mealtime behavior survey to assess early history regarding feeding difficulties, mealtime location, problematic mealtime behaviors, and food preferences and restrictions [19]. Children and adolescents up to 17 years old were included in the current study, and to better understand any apparent age differences in problematic mealtime behaviors, we conducted comparison analyses among three sub-age groups (early childhood, mid-childhood, and adolescents). The objectives of this study were (1) to assess early history of feeding difficulties, mealtime location, problematic mealtime behaviors, and food preferences and restrictions of children with ASD in Florida; (2) to examine whether the results are different by age group; and (3) to compare the results from children aged 3 to 6 in our sample to reference data from Provost et al. [19]. The measurement was used to systematically compare the eating behaviors of young children with ASD $(n=24)$ to those of typically developing children $(n=24)$; therefore, their data on typically developing children were used as reference data and were compared to the data of young children from the current study.

\section{Materials and Methods}

\subsection{Participant Recruitment and Screening Procedure}

This cross-sectional survey study recruited parents who have a child aged younger than 18 years and clinically diagnosed with ASD living in Florida. Through the Center for Autism and Related Disabilities (CARD), other local centers for autism, clinics, and schools, parents were invited to participate in the study from July 2017 until March 2018. A flyer with the research coordinator's contact information was sent out to parents or posted on social media sites with permission. ASD diagnosis performed by one or more clinical professionals among neurologist, developmental pediatrician, psychiatrist, clinical psychologist, pediatrician, or primary care physician was required to be included in the study. Exclusion criteria included having a serious medical condition that required special treatment or on medication that could affect child's appetite and body weight such as Olanzapine, Risperidone, or Aripiprazole to avoid potential influences on eating habits or mealtime behaviors. No participant was excluded during the screening process. Sixty parents contacted the research team, and 41 parents completed the survey (68.3\% participation rate). A main reason for low responders was a severe hurricane in September 2017; some became overwhelmed by the situation, and some lost interest after a while. The rest did not respond to several follow-up messages without providing reasons.

\subsection{Demographic Characteristics}

Table 1 shows demographic characteristics of the study participants. The majority of the children in our sample (73\%) were boys and White $(39 \%)$ or Hispanic (34\%). The majority of parent participants were mother of the child (95\%) and had an Associate's degree or higher (68\%). The mean age of the parents was 40.3 years. Breakdowns of demographic characteristics by children's age group (early childhood $=2-6$ years, mid-childhood $=7-11$ years, and adolescents $=12-17$ years) are also presented in Table 1 . There were high percentages of Hispanic participants in the early childhood group (44\%) 
and in the adolescent group (46\%), while the majority of participants were White in the mid-childhood group $(64 \%)$.

Table 1. Demographic characteristics of study participants.

\begin{tabular}{|c|c|c|c|c|}
\hline Variables & $\begin{array}{l}\text { Total Sample 2-17 } \\
\text { Years }(n=41)\end{array}$ & $\begin{array}{l}\text { Early Childhood } \\
2-6 \text { Years }(n=16)\end{array}$ & $\begin{array}{l}\text { Mid-Childhood } \\
\text { 7-11 Years }(n=14)\end{array}$ & $\begin{array}{l}\text { Adolescents 12-17 } \\
\text { Years }(n=11)\end{array}$ \\
\hline \multicolumn{5}{|l|}{ Child with ASD demographics } \\
\hline Age (years) ${ }^{a}$ & $8.3 \pm 4.02$ & $4.25 \pm 1.18$ & $8.64 \pm 1.55$ & $13.55 \pm 1.86$ \\
\hline \multicolumn{5}{|l|}{ Gender } \\
\hline Boys & $30(73 \%)$ & $12(75 \%)$ & $11(79 \%)$ & $7(64 \%)$ \\
\hline \multicolumn{5}{|l|}{ Race/ethnicity } \\
\hline Hispanic or Latino & $14(34 \%)$ & $7(44 \%)$ & $2(14 \%)$ & $5(46 \%)$ \\
\hline Asian & $1(2 \%)$ & $1(6 \%)$ & $0(0 \%)$ & $0(0 \%)$ \\
\hline Other & $7(17 \%)$ & $4(25 \%)$ & $2(14 \%)$ & $1(9 \%)$ \\
\hline \multicolumn{5}{|l|}{ Parent demographics } \\
\hline Mother & $39(95 \%)$ & $15(94 \%)$ & $14(100 \%)$ & $10(91 \%)$ \\
\hline Hispanic & $14(34 \%)$ & $7(44 \%)$ & $2(14 \%)$ & $5(46 \%)$ \\
\hline Asia & $1(2 \%)$ & $1(6 \%)$ & $0(0 \%)$ & $0(0 \%)$ \\
\hline Other & $2(5 \%)$ & $0(0 \%)$ & $1(7 \%)$ & $1(9 \%)$ \\
\hline \multicolumn{5}{|l|}{ Highest level of education } \\
\hline High school diploma or equivalent & $1(2 \%)$ & $0(0 \%)$ & $1(7 \%)$ & $0(0 \%)$ \\
\hline Some college, no degree & $12(29 \%)$ & $7(44 \%)$ & $2(14 \%)$ & $3(27 \%)$ \\
\hline Associate's degree & $5(12 \%)$ & $2(13 \%)$ & $1(7 \%)$ & $2(18 \%)$ \\
\hline University or 4-year degree & $11(27 \%)$ & $3(19 \%)$ & $6(43 \%)$ & $2(18 \%)$ \\
\hline Post-college or graduate degree & $12(29 \%)$ & $4(25 \%)$ & $4(29 \%)$ & $4(36 \%)$ \\
\hline
\end{tabular}

${ }^{\text {a }}$ Mean \pm standard deviation. NA represents not available.

\subsection{Instrument and Data Collection}

Parents completed a 48-question survey via Qualtrics online software. A paper-and-pencil version of an instrument developed by Provost et al. [19] was obtained and transferred verbatim into an online format. The authors reported that face and content validity was conducted by an interdisciplinary panel of experts with extensive experience working with children with ASD, and the instrumentation was pilot tested with a group of families and suggestions were incorporated into the final version [19]. The survey provides primarily nominal data (e.g., yes/no answers, checklists, open-ended questions) on early history, mealtime location, mealtime behaviors, and food preferences and restrictions. The questions were divided into four sections: Early History, Mealtime Environment, Child Likes and Dislikes, and Parental Views.

Three questions on Early History included, "Are you nursing or did you nurse your child?"; "How would you have described your child's eating behavior in the first three months of life?"; and "Did you have any concerns about your child's eating when your child was: (a) Birth to 1 year, (b) 1 year to 2 years, (c) 2 years to 3 years, and (d) 3 years to present?"

Ten questions belonged to the Mealtime Environment section. Mealtime location was measured with one question, "Does your child have difficulty eating at: Home, school, fast-food restaurants, regular restaurants, picnics, relatives' homes, friends' home, or other places?" Parents were asked to check all response options that apply to them. Examples of other questions in the Mealtime Environment section included types of utensils, whether a child eats independently, who monitors the child's mealtimes, where the child eats, and how parents know when to feed their children.

Fourteen questions asked child's preferences and restrictions in the Child Likes and Dislikes section. Questions included food preferences, craving or avoiding certain foods, favorite food textures, temperature, colors, or food packaging, or whether the child smelled food before eating or mouthing/swallowing non-food items. Two questions asked whether the child required food to be 
prepared a special way and whether the child ate the same food in a repetitive manner every day, which indicate issues with routines or rituals.

The section on Parental Views included 21 questions on mealtime behaviors, health concerns, food allergies, special diet, and other eating and lifestyle issues and concerns. Mealtime behaviors were asked with one checklist type question with 19 mealtime related problematic behavior response options.

A total mealtime behavior score, a sum of 44 items from different sections, was calculated [19]. The total score represents overall problems associated with mealtime behavior and food habits, and a higher score indicates more problematic mealtime behaviors. The Cronbach's alpha value for internal consistency reliability was 0.82 with our sample, suggesting high internal consistency [20].

Potential participants who initially contacted the project coordinator were invited for the survey. Personal survey links were emailed to parents for them to complete the survey online. Follow-up messages were sent periodically if necessary. The consent process was done through the instructional page of the survey. Details of research description, risks and benefits, confidentiality, and how survey results will be used were presented and a downloadable pdf file was available for parent. Parents were informed that they could withdraw from the study at any time. The study protocol was approved by the Institutional Review Board of University of South Florida.

\subsection{Statistical Analysis}

Descriptive statistics were performed for all survey questions, and analyses were performed in two steps. First, subgroup data from children aged 3 to 6 years were compared to the results of Provost et al. [19] to evaluate whether the results from this study differ from the ones in the reference study. Second, data from our whole sample were broken down into early childhood (ages 2-6 years), mid-childhood (ages 7-11 years) and adolescents (ages 12-17 years) to compare results within our sample.

To compare data of children aged 3 to 6 years between our subgroup and the reference, Fisher's exact test was used for count data and summary independent-samples t-test was performed for the total mealtime behavior score. Frequencies, means, and standard deviations from the original study were extracted and used in the comparison analyses. Chi square tests and Kruskal Wallis tests were used to compare data within our sample by age group. Descriptive statistics and $\mathrm{t}$-tests were analyzed with Statistical Package for the Social Sciences (SPSS) version 24.0 (IBM SPSS, Inc., Chicago, IL, USA). An online analytical software GraphPad QuickCalcs was used for Fischer's exact test.

\section{Results}

\subsection{Results by Age Group}

\subsubsection{Early History}

Early history results by age group are presented in Table 2. For all age groups, half or more of parents reported that they nursed their children (50\% to 88\%) and experienced difficulties breastfeeding ( $57 \%$ to $64 \%$ ). Fewer early feeding concerns ( $0-3$ years) were reported in mid-childhood and adolescents compared to those in early childhood. However, feeding concerns at ages 3 and older was high for all three age groups (75\% in early childhood, $86 \%$ in mid-childhood, and $73 \%$ in adolescents) with no statistically significant difference.

Having no difficulty eating in any setting and eating a variety of foods were more frequently reported by parents of children aged 7 and older. Only one parent $(6 \%)$ in the early childhood group reported no difficulty eating in any setting and eating a variety of foods. The percentage of parents who reported that their children have no difficulty eating in any setting increased to $14 \%$ in the mid-childhood group and $27 \%$ in the adolescent group, while the percent who reported that their children eat a variety of foods increased to $36 \%$ in the mid-childhood group and nearly half $(46 \%)$ in the adolescent group. 
Table 2. Early history by age group.

\begin{tabular}{|c|c|c|c|c|}
\hline Item & $\begin{array}{c}\text { Early } \\
\text { Childhood 2-6 } \\
\text { Years }(n=16)\end{array}$ & $\begin{array}{l}\text { Mid-Childhood } \\
\text { 7-11 Years } \\
(n=14)\end{array}$ & $\begin{array}{l}\text { Adolescents } \\
\text { 12-17 Years } \\
\quad(n=11)\end{array}$ & $\begin{array}{l}\text { Chi-Square } \\
\text { Test, } p \text {-Value }\end{array}$ \\
\hline \multicolumn{5}{|l|}{ Nursing } \\
\hline Nurse your child & $14(88 \%)$ & $7(50 \%)$ & $7(64 \%)$ & 0.082 \\
\hline Difficulties with breastfeeding ${ }^{\text {a }}$ & $9(64 \%)$ & $4(57 \%)$ & $4(57 \%)$ & 0.810 \\
\hline \multicolumn{5}{|l|}{ Eating behavior in first 3 months (bottle or breastfeeding) } \\
\hline Strong continuous suck taking $10-15 \mathrm{~min}$. Easy to feed. & $4(25 \%)$ & $6(43 \%)$ & $5(46 \%)$ & 0.464 \\
\hline $\begin{array}{l}\text { Strong continuous suck but frequent breaks requiring to } \\
\text { redirect }\end{array}$ & $2(13 \%)$ & $3(21 \%)$ & $2(18 \%)$ & 0.805 \\
\hline $\begin{array}{l}\text { Unorganized sucking behavior requiring your assistance } \\
\text { Slow eater }\end{array}$ & $5(31 \%)$ & $6(43 \%)$ & $1(9 \%)$ & 0.179 \\
\hline $\begin{array}{l}\text { Irritable eater, fidgety, frequent release of nipple with } \\
\text { crying }\end{array}$ & $1(6 \%)$ & $2(14 \%)$ & $1(9 \%)$ & 0.758 \\
\hline Required frequent feedings & $4(25 \%)$ & $4(29 \%)$ & $3(27 \%)$ & 0.975 \\
\hline $\begin{array}{l}\text { Gagging, choking, facial grimacing and spitting up. } \\
\text { Difficult to feed }\end{array}$ & $3(19 \%)$ & $2(14 \%)$ & $0(0 \%)$ & 0.328 \\
\hline \multicolumn{5}{|l|}{ Concerns about eating } \\
\hline Feeding concerns, birth to 1 year & $7(44 \%)$ & $11(79 \%)$ & $6(55 \%)$ & 0.147 \\
\hline Feeding concerns, $1-2$ years & $10(63 \%)$ & $8(57 \%)$ & $5(46 \%)$ & 0.678 \\
\hline Feeding concerns, $2-3$ years & $14(88 \%)$ & $8(57 \%)$ & $5(46 \%)$ & 0.054 \\
\hline Feeding concerns, 3 years to present & $12(75 \%)$ & $12(86 \%)$ & $8(73 \%)$ & 0.688 \\
\hline
\end{tabular}

${ }^{a}$ Percentage is derived from total participants who nursed their child.

\subsubsection{Mealtime Environment}

Table 3 presents mealtime environment results by age group. While half or more parents $(50 \%$ to $69 \%$ ) of children in the early childhood group reported eating difficulties for all seven locations, most parents did not report difficulties at these locations for mid-childhood and adolescents. Regarding eating difficulties, statistically significant differences were detected for eating difficulty at home $(p=0.013)$, at fast food restaurants $(p=0.005)$, and at regular restaurants $(p=0.016)$ by age group, with prevalence decreasing with age for all three variables. Regarding the ways in which parents get their children to eat, there were statistically significant differences for getting children to eat by using positive reinforcements $(p=0.02)$ and for the child eating automatically without assistance $(p=0.037)$, with prevalence decreasing and increasing with age, respectively.

Table 3. Mealtime environment by age group.

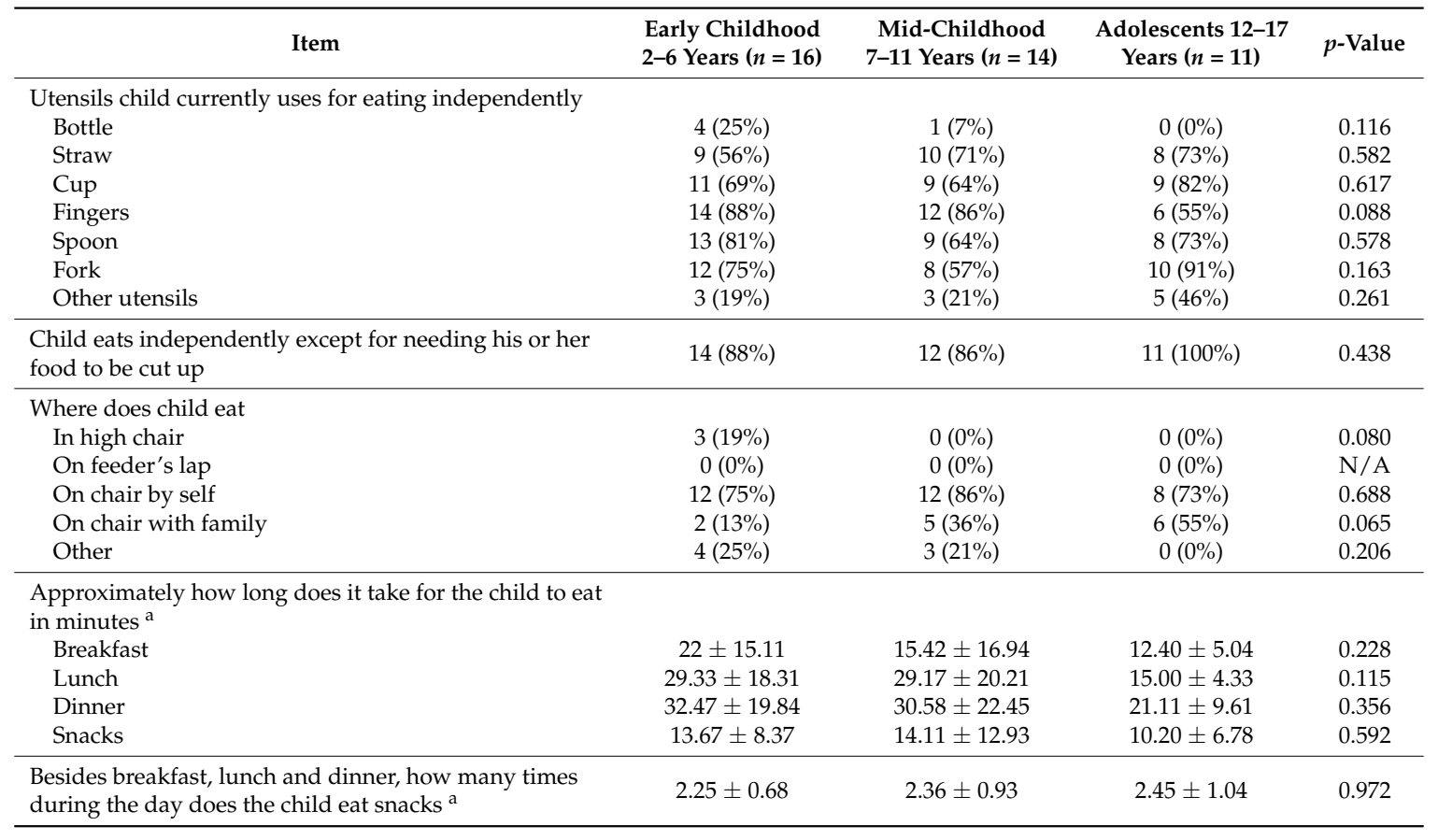


Table 3. Cont.

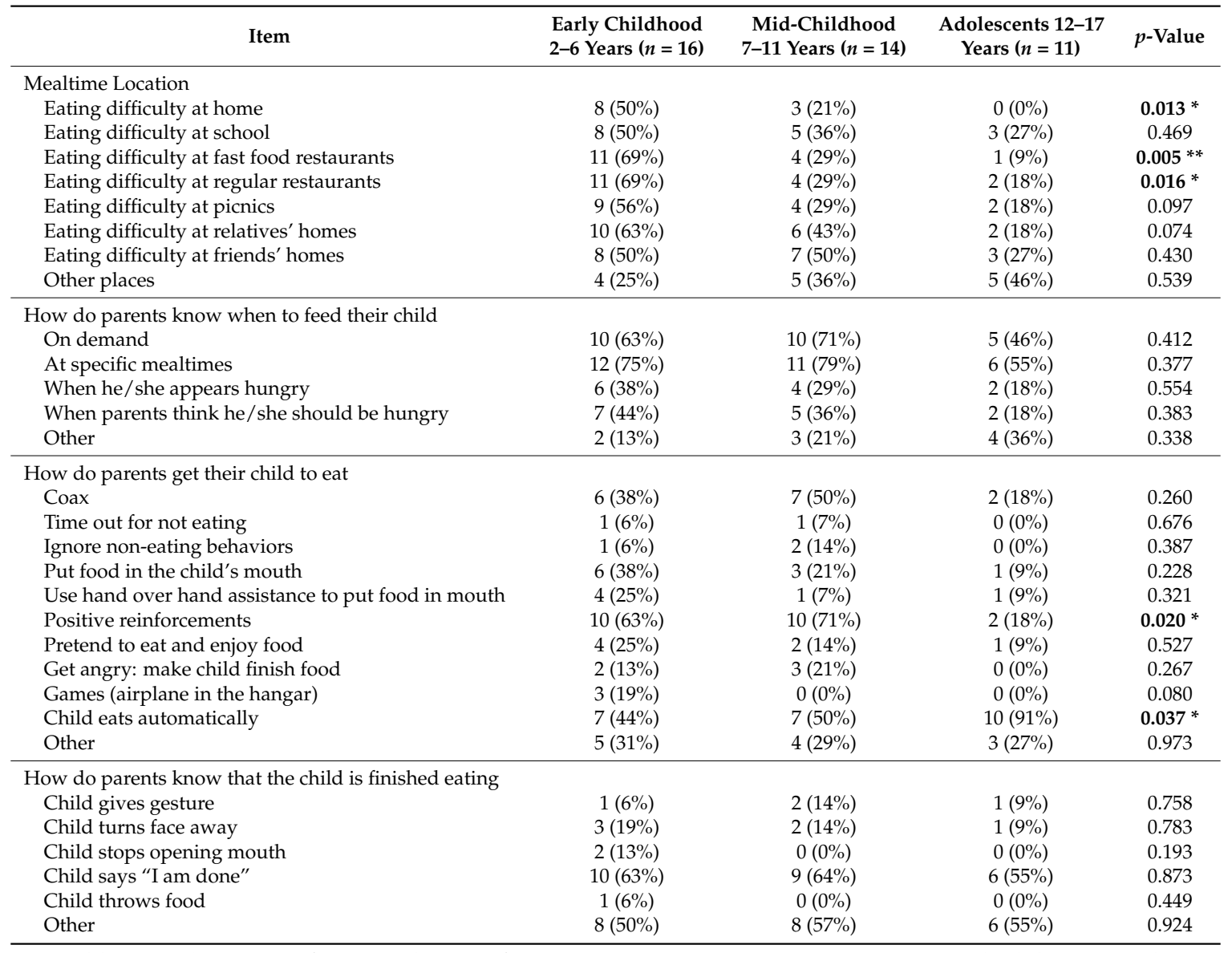

Bold type indicates significant results; Significance at: ${ }^{*} p<0.05,{ }^{* *} p<0.01 ;{ }^{\text {a }}$ Mean \pm standard deviation; Chi square test used for categorical variables and Kruskal Wallis test used for continuous variables.

\subsubsection{Child Likes and Dislikes}

The results on parent-reported child likes and dislikes indicate that some food preferences were reported nearly in all age groups ( $88 \%$ in the early childhood, and $100 \%$ in both mid-childhood and adolescents). Child craving certain foods was reported by $88 \%$ of parents in the early childhood group, $79 \%$ of parents in the mid-childhood group, and $46 \%$ of parents in the adolescent group $(p=0.045)$. The most commonly reported food resistance/restrictions across all age groups were avoiding certain foods (94\% in early childhood, $93 \%$ in mid-childhood, and $91 \%$ in adolescents ) and resisting trying new foods ( $81 \%$ in early childhood, $71 \%$ in mid-childhood, and $82 \%$ in adolescents ). There was a statistically significant age difference for requiring foods to be prepared in a special way $(69 \%$ in early childhood, 36\% in mid-childhood, and $18 \%$ in adolescents; $p=0.025)$, with prevalence decreasing with age. Eating the same food in a repetitive manner ( $44 \%$ in early childhood, $64 \%$ in mid-childhood, and $36 \%$ in adolescents) was a common feature in all age groups with no statistical difference.

\subsubsection{Parental Views}

Parental views on mealtime behaviors, issues with routines or rituals, and eating problems decreased with age, while some characteristics were highest in the mid-childhood age group. The most commonly reported mealtime behavior was being a picky eater, which was reported by $75 \%$ of parents of children in the early childhood group, $71 \%$ in the mid-childhood group, and $46 \%$ in the adolescent group. The second most commonly reported behavior was leaving the table frequently, which was reported by $71 \%$ of the mid-childhood group, $50 \%$ of the early childhood group, and $27 \%$ of the adolescent group. Stuffing mouth or cheeks was also a commonly reported eating problem, which was 
reported by $50 \%$ of parents in the early childhood group, $21 \%$ in the mid-childhood group, and $27 \%$ in the adolescent group.

Statistically significant differences by age group were detected for gagging ( $31 \%$ in early childhood, $7 \%$ in mid-childhood, and $0 \%$ in adolescents; $p=0.049)$, child playing with his / her food (50\% in early childhood, $29 \%$ in mid-childhood, and $0 \%$ in adolescents; $p=0.019)$, and eating very slowly (56\% in early childhood, $71 \%$ in mid-childhood, and $18 \%$ in adolescents; $p=0.027$ ). In addition, there was a statistically significant difference for whether parents reported mealtime with their children to be stressful, O.K., or fun ( $p=0.036)$, with the majority of parents $(56 \%)$ in the early childhood group reporting mealtime to be stressful, and the majority of parents in the mid-childhood and adolescent groups (64\% for each group) reporting mealtime to be O.K. Not surprisingly, the child was reported to be toilet trained for urine $(p=0.018)$, with prevalence increasing with age.

Parents reported a variety of health concerns and special diets, and there was no statistically significant difference by age group. The most commonly reported health concern that the child experienced in the past was an ear infection (31\% in early childhood, $43 \%$ in mid-childhood, and $64 \%$ in adolescents), while the most frequently reported health concerns that parents currently have was having to take medications (13\% in early childhood, $50 \%$ in mid-childhood, and $27 \%$ in adolescents). Regarding special diets, parents reported that they currently apply avoiding food additives/color (31\% in early childhood, $14 \%$ in mid-childhood, and $27 \%$ in adolescents), gluten free diet (6\% in early childhood, 14\% in mid-childhood, and 9\% in adolescents), lactose free diet (19\% in early childhood, $21 \%$ in mid-childhood, and $9 \%$ in adolescents), or casein free diet (13\% in early childhood, $14 \%$ in mid-childhood, and $9 \%$ in adolescents). Some parents reported that they tried these various special diets in the past, on average for about 2 to 5 months, for their children. Notably, parents in the adolescent group reported that they tried lactose-free diet (36\%) and/or casein-free diet (36\%) in the past, and among those, one parent reported that the child is still on both lactose-free and casein-free diet.

\subsubsection{Total Score for Mealtime Behavior Scale}

The total mealtime behavior score ranged from 6 to 22 with a mean of $15.88(\mathrm{SD}=4.96)$ for the early childhood group, from 3 to 24 with a mean of 13.57 (SD = 6.36) for the mid-childhood group, and from 2 to 15 with a mean of $7.91(\mathrm{SD}=4.41)$ for the adolescent group. The mean scores for the early childhood $(p<0.001)$ and mid-childhood groups $(p=0.005)$ were significantly higher compared to the one in the adolescent group, indicating significantly more problematic mealtime behaviors.

\subsection{Replication Study: Comparisons between a Sample of 3-6 Years Old Children with ASD from the Current Study and the Reference Data from Provost et al. [19]}

The mean age of the sample of 3-6 years old children with ASD in the current study was 4.4 years $(\mathrm{SD}=1.06)$, similar to the ones $(4.3$ years both in the ASD and the typically developing groups) in the Provost et al. [19]. The percentage of boys in the current study (73\%) was also similar to the ones in the reference study ( $75 \%$ both in the ASD and the typically developing children). The compositions of race/ethnicity were slightly different between the current study and the reference study. The percentages of Hispanic or Latino were similar (40\% in the current study vs. $46 \%$ in the reference study). However, there was a higher percentage of other race/ethnicity in the current study ( $27 \%$ in the current study vs. $4 \%$ in the reference study), while there was a higher percentage of White in the reference study ( $27 \%$ in the current study vs. $50 \%$ in the reference study).

\subsubsection{Early History}

Table 4 presents results regarding early history compared to the reference data. In our sample, 13 out of 15 mothers nursed their children, and 69\% reported difficulties with breastfeeding, which was significantly greater from the $15 \%$ of mothers who reported difficulties with breastfeeding in typically developing children. A significantly lower percentage of participants in our sample reported strong continuous sucking behavior compared to the reference data for both ASD and typically developing 
children. There were significantly more parents in our sample who reported feeding concerns when their children were 1-2 years, 2-3 years, and from 3 years of age until present compared to those of typically developing children in the reference sample. Significantly fewer parents of children with ASD in our sample reported that their children have no difficulty eating in any setting (7\%) and eat a variety of foods $(7 \%)$ compared to the typically developing reference data (50\% and $58 \%$, respectively).

Table 4. Early history of feeding and eating behaviors.

\begin{tabular}{|c|c|c|c|}
\hline \multirow[b]{2}{*}{ Item } & \multirow{2}{*}{$\begin{array}{l}\text { Current Study } \\
\begin{array}{l}\text { ASD 3-6 Years } \\
(n=15)\end{array}\end{array}$} & \multicolumn{2}{|c|}{ Reference Study a } \\
\hline & & $\begin{array}{l}\text { ASD 3-6 Years } \\
\quad(n=24)\end{array}$ & $\begin{array}{c}\text { Typically Developing } \\
\text { Children 3-6 Years } \\
(n=24)\end{array}$ \\
\hline \multicolumn{4}{|l|}{ Nursing } \\
\hline Nurse your child & $13(87 \%)$ & $18(75 \%)$ & $20(83 \%)$ \\
\hline Difficulties with breastfeeding ${ }^{b}$ & $9(69 \%)$ & $7(39 \%)$ & $3(15 \%) *$ \\
\hline \multicolumn{4}{|l|}{ Eating behavior in first 3 months (bottle or breastfeeding) } \\
\hline Strong continuous suck taking $10-15 \mathrm{~min}$. Easy to feed & $4(27 \%)$ & $15(63 \%) *$ & $19(79 \%) * *$ \\
\hline $\begin{array}{l}\text { Strong continuous suck but frequent breaks requiring to } \\
\text { redirect }\end{array}$ & $2(13 \%)$ & $2(8 \%)$ & $2(8 \%)$ \\
\hline $\begin{array}{l}\text { Unorganized sucking behavior requiring your assistance. } \\
\text { Slow eater }\end{array}$ & $5(33 \%)$ & $5(21 \%)$ & $1(4 \%) *$ \\
\hline Irritable eater, fidgety, frequent release of nipple with crying & $1(7 \%)$ & $4(17 \%)$ & $0(0 \%)$ \\
\hline Required frequent feedings & $4(27 \%)$ & $11(46 \%)$ & $7(30 \%)$ \\
\hline $\begin{array}{l}\text { Gagging, choking, facial grimacing and spitting up. } \\
\text { Difficult to feed }\end{array}$ & $2(13 \%)$ & $5(21 \%)$ & $3(13 \%)$ \\
\hline \multicolumn{4}{|l|}{ Concerns about eating } \\
\hline Feeding concerns, birth to 1 year & $7(47 \%)$ & $9(38 \%)$ & $7(30 \%)$ \\
\hline Feeding concerns, $1-2$ years & $10(67 \%)$ & $12(50 \%)$ & $2(8 \%) * * *$ \\
\hline Feeding concerns, $2-3$ years & $14(93 \%)$ & $17(71 \%)$ & $4(17 \%) * * *$ \\
\hline Feeding concerns, 3 years to present & $12(80 \%)$ & $16(67 \%)$ & $4(17 \%) * * *$ \\
\hline \multicolumn{4}{|l|}{ Current overview } \\
\hline Has no difficulty eating in any setting & $1(7 \%)$ & $5(21 \%)$ & $12(50 \%) * *$ \\
\hline Eats a variety of foods & $1(7 \%)$ & $3(13 \%)$ & $14(58 \%) * *$ \\
\hline
\end{tabular}

${ }^{a}$ Provost et al. (2010) [19]; ${ }^{b}$ Percentage is derived from total participants who nursed their child; Bold type indicates significant results; Fisher's exact test significance at: ${ }^{*} p<0.05,{ }^{* *} p<0.01,{ }^{* * *} p<0.001$.

\subsubsection{Mealtime Location}

Results regarding mealtime locations are presented in Table 5. Compared to the reference data, significantly more parents of children in our sample reported that their children have eating difficulties at home (47\%) and at fast food restaurants $(67 \%)$ than both ASD (13\% and $21 \%)$ and typically developing children (13\% and 17\%) from the reference data, respectively. In addition, $47 \%$ of parents in our sample reported that their children have eating difficulties at school, while no parents of typically developing children from the reference sample reported eating difficulties at school $(p<0.001)$. Eight parents $(53 \%)$ from our sample reported that their children have eating difficulties at picnics, which was significantly different from the typically developing children reference data $(17 \% ; p<0.05)$. 
Table 5. Eating difficulties at mealtime locations.

\begin{tabular}{|c|c|c|c|}
\hline \multirow[b]{2}{*}{ Item } & \multirow{2}{*}{$\begin{array}{l}\text { Current Study } \\
\begin{array}{c}\text { ASD 3-6 Years } \\
(n=15)\end{array}\end{array}$} & \multicolumn{2}{|c|}{ Reference Study ${ }^{a}$} \\
\hline & & $\begin{array}{c}\text { ASD 3-6 Years } \\
(n=24)\end{array}$ & $\begin{array}{c}\text { Typically Developing } \\
\text { Children 3-6 Years } \\
(n=24)\end{array}$ \\
\hline \multicolumn{4}{|l|}{ Mealtime Location } \\
\hline Eats only in specific places & $1(7 \%)$ & $5(21 \%)$ & $1(4 \%)$ \\
\hline Eating difficulty at home & $7(47 \%)$ & $3(13 \%) *$ & $3(13 \%) *$ \\
\hline Eating difficulty at school & $7(47 \%)$ & $6(25 \%)$ & $0(0 \%) * * *$ \\
\hline Eating difficulty at fast food restaurants & $10(67 \%)$ & $5(21 \%) * *$ & $4(17 \%) * *$ \\
\hline Eating difficulty at regular restaurants & $10(67 \%)$ & $13(54 \%)$ & $2(8 \%) * * *$ \\
\hline Eating difficulty at picnics & $8(53 \%)$ & $9(38 \%)$ & $4(17 \%) *$ \\
\hline Eating difficulty at relatives' homes & $9(60 \%)$ & $11(46 \%)$ & $7(29 \%)$ \\
\hline Eating difficulty at friends' homes & $7(47 \%)$ & $12(50 \%)$ & $7(29 \%)$ \\
\hline
\end{tabular}

a Provost et al. (2010) [19]; Bold type indicates significant results; Fisher's exact test significance at: ${ }^{*} p<0.05$, ** $p<0.01,{ }^{* * *} p<0.001$.

\subsubsection{Parental Views on Mealtime Behaviors, Issues with Routines or Rituals and Eating Problems}

Table 6 shows parental views on mealtime behaviors, issues with routines and rituals, and various eating problems. Most participants in our sample reported that their children leave the table frequently at mealtime $(51 \%)$ and are picky eaters $(66 \%)$. There were $39 \%$ who reported their children to be restless but sit during meals, $32 \%$ as inconsistent eaters, and $22 \%$ as ritualistic eaters. Significantly more parents of children with ASD in our sample identified their children as picky eaters $(73 \%$ vs. $25 \%$ ) and as having problems with gagging while eating (33\% vs. $0 \%$ ), compared to the reference sample of typically developing children (all $p<0.01$ ). Additionally, significantly more parents in our sample reported that their child requires food prepared in a special way ( $67 \%$ vs. $25 \%)$, eats the same food in a repetitive manner ( $47 \%$ vs. $13 \%$ ) and stuffs mouth or cheeks during eating ( $53 \%$ vs. $13 \%$ ) compared to the reference sample of typically developing children (all $p<0.05)$. A significantly smaller number of parents reported their child as a ritualistic eater in our sample compared to the reference sample of children with ASD $(20 \%$ vs. $33 \% ; p<0.05)$.

Table 6. Parental views on mealtime behaviors, issues with routines or rituals, and eating problems.

\begin{tabular}{|c|c|c|c|}
\hline \multirow[b]{2}{*}{ Item } & \multirow{2}{*}{$\begin{array}{l}\text { Current Study } \\
\begin{array}{l}\text { ASD 3-6 Years } \\
(n=15)\end{array}\end{array}$} & \multicolumn{2}{|c|}{ Reference Study ${ }^{a}$} \\
\hline & & $\begin{array}{c}\text { ASD 3-6 Years } \\
\quad(n=24)\end{array}$ & $\begin{array}{l}\text { Typically Developing } \\
\text { Children 3-6 Years } \\
(n=24)\end{array}$ \\
\hline \multicolumn{4}{|l|}{ Mealtime behaviors: My child, } \\
\hline Leaves table frequently & $8(53 \%)$ & $14(58 \%)$ & $7(29 \%)$ \\
\hline Restless but sits & $9(60 \%)$ & $12(50 \%)$ & $11(46 \%)$ \\
\hline Resists sitting at table & $3(20 \%)$ & $11(46 \%)$ & $3(13 \%)$ \\
\hline Seems fearful sitting at & $0(0 \%)$ & $0(0 \%)$ & $1(4 \%)$ \\
\hline Rocks during meals & $1(7 \%)$ & $1(4 \%)$ & $0(0 \%)$ \\
\hline Hits self while eating & $0(0 \%)$ & $1(4 \%)$ & $0(0 \%)$ \\
\hline Has frequent tantrums & $1(7 \%)$ & $6(25 \%)$ & $0(0 \%)$ \\
\hline Uses only specific utensils & $2(13 \%)$ & $4(17 \%)$ & $0(0 \%)$ \\
\hline Throws/dumps food & $1(7 \%)$ & $8(33 \%)$ & $1(4 \%)$ \\
\hline Spits food & $0(0 \%)$ & $5(21 \%)$ & $1(4 \%)$ \\
\hline Is a picky eater & $11(73 \%)$ & $18(75 \%)$ & $6(25 \%) * *$ \\
\hline Is an inconsistent eater & $7(47 \%)$ & $10(42 \%)$ & $10(42 \%)$ \\
\hline \multicolumn{4}{|l|}{ Issues with routines or rituals: My child, } \\
\hline Is a ritualistic eater & $3(20 \%)$ & $8(33 \%)$ & $2(8 \%)$ \\
\hline Requires food prepared in a special way & $10(67 \%)$ & $12(50 \%)$ & $6(25 \%) *$ \\
\hline Eats same food in a repetitive manner & $7(47 \%)$ & $10(42 \%)$ & $3(13 \%) *$ \\
\hline Has routines or rituals with food or eating & $2(13 \%)$ & $9(38 \%)$ & $4(17 \%)$ \\
\hline Is upset if routine is broken & $3(20 \%)$ & $6(25 \%)$ & $3(13 \%)$ \\
\hline Needs food in specific place on plate & $1(7 \%)$ & $3(13 \%)$ & $0(0 \%)$ \\
\hline
\end{tabular}


Table 6. Cont.

\begin{tabular}{|c|c|c|c|}
\hline \multirow[b]{2}{*}{ Item } & \multirow{2}{*}{$\begin{array}{l}\text { Current Study } \\
\begin{array}{l}\text { ASD 3-6 Years } \\
(n=15)\end{array}\end{array}$} & \multicolumn{2}{|c|}{ Reference Study ${ }^{a}$} \\
\hline & & $\begin{array}{c}\text { ASD 3-6 Years } \\
\quad(n=24)\end{array}$ & $\begin{array}{c}\text { Typically Developing } \\
\text { Children 3-6 Years } \\
(n=24)\end{array}$ \\
\hline \multicolumn{4}{|l|}{ My child has problems with } \\
\hline Gagging & $5(33 \%)$ & $8(33 \%)$ & $0(0 \%) * *$ \\
\hline Chewing & $0(0 \%)$ & $0(0 \%)$ & $0(0 \%)$ \\
\hline Swallowing & $0(0 \%)$ & $5(21 \%)$ & $0(0 \%)$ \\
\hline Sucking & $0(0 \%)$ & $0(0 \%)$ & $0(0 \%)$ \\
\hline Throwing up & $0(0 \%)$ & $0(0 \%)$ & $0(0 \%)$ \\
\hline Nausea & $1(7 \%)$ & $2(8 \%)$ & $0(0 \%)$ \\
\hline Stuffing mouth or cheeks & $8(53 \%)$ & $8(33 \%)$ & $3(13 \%) *$ \\
\hline
\end{tabular}

${ }^{a}$ Provost et al. (2010) [19]; Bold type indicates significant results; Fisher's exact test significance at: ${ }^{*} p<0.05$, ** $p<0.01$.

\subsubsection{Food Preferences and Restrictions}

Table 7 reports results of food preferences, food resistance/restrictions, and smelling/mouthing of food items. Significantly more parents of children in our sample reported that their children crave certain foods ( $93 \%$ vs. $54 \%$ ) and mouth non-food items (46\% vs. $13 \%$ ) compared to the typically developing reference group (both $p<0.05$ ). Significantly more parents of children with ASD in our sample $(60 \%)$ indicated that their children have favorite food textures compared to the reference sample of typically developing children $(4 \% ; p<0.001)$. Other food preferences and restrictions were not significantly different from the reference data.

Table 7. Food preferences and restrictions.

\begin{tabular}{|c|c|c|c|}
\hline \multirow[b]{2}{*}{ Item } & \multirow{2}{*}{$\begin{array}{l}\text { Current Study } \\
\begin{array}{l}\text { ASD 3-6 Years } \\
(n=15)\end{array}\end{array}$} & \multicolumn{2}{|c|}{ Reference Study ${ }^{a}$} \\
\hline & & $\begin{array}{l}\text { ASD 3-6 Years } \\
\quad(n=24)\end{array}$ & $\begin{array}{c}\text { Typically Developing } \\
\text { Children 3-6 Years } \\
(n=24)\end{array}$ \\
\hline \multicolumn{4}{|l|}{ Food craving and preferences } \\
\hline Child craves certain foods & $14(93 \%)$ & $20(83 \%)$ & $13(54 \%) *$ \\
\hline Has food preferences & $14(93 \%)$ & $23(96 \%)$ & $21(88 \%)$ \\
\hline Has favorite food textures & $9(60 \%)$ & $17(71 \%)$ & $1(4 \%) * * *$ \\
\hline Has favorite food colors & $1(7 \%)$ & $8(33 \%)$ & $2(8 \%)$ \\
\hline Prefers certain food temperature & $9(60 \%)$ & $11(46 \%)$ & $12(50 \%)$ \\
\hline \multicolumn{4}{|l|}{ Food resistance/restrictions } \\
\hline Child avoids certain foods & $14(93 \%)$ & $22(92 \%)$ & $16(67 \%)$ \\
\hline Resists trying new food & $12(80 \%)$ & $22(92 \%)$ & $12(50 \%)$ \\
\hline Limits food to favorite foods & $4(27 \%)$ & $10(42 \%)$ & $5(21 \%)$ \\
\hline Limits food to favorite texture & $3(20 \%)$ & $9(38 \%)$ & $1(4 \%)$ \\
\hline Limits food to favorite colors & $0(0 \%)$ & $1(4 \%)$ & $1(4 \%)$ \\
\hline Limits food to preferred temperature & $4(27 \%)$ & $5(21 \%)$ & $4(17 \%)$ \\
\hline Limits food to preferred packaging & $2(13 \%)$ & $2(8 \%)$ & $0(0 \%)$ \\
\hline \multicolumn{4}{|l|}{ Smelling/mouthing } \\
\hline Smells food before eating & $6(40 \%)$ & $5(21 \%)$ & $6(25 \%)$ \\
\hline Mouths nonfood items & $7(47 \%)$ & $13(54 \%)$ & $3(13 \%) *$ \\
\hline Swallows nonfood items & $3(20 \%)$ & $6(25 \%)$ & $1(4 \%)$ \\
\hline
\end{tabular}

${ }^{a}$ Provost et al. (2010) [19]; Bold type indicates significant results; Fisher's exact test significance at: ${ }^{*} p<0.05$, $* * * p<0.001$.

\subsubsection{Total Score for Mealtime Behavior Scale}

The total mealtime behavior score was constructed from 44 items included in Tables 2-5 and can range from 0 to 44 , with a higher score indicating more problems associated with mealtime behavior and food habits. A significant difference was found in mean total score between children with ASD 
aged 3-6 years in this study (mean $=15.93, \mathrm{SD}=5.13$ ) and typically developing children from Provost et al. (mean $=6.3, \mathrm{SD}=4.3 ; p<0.001$ ). The higher mean mealtime behavior score in children with ASD suggests significantly more problematic behaviors compared to typically developing children. There was no significant difference between children with ASD from this study and those with ASD from the reference data.

\section{Discussion}

In this study, a survey tool [19] was used to examine early history, mealtime environment, food preferences, and parental views on mealtime and eating behaviors among children with ASD in Florida. Parents who had children aged 2-17 years with ASD completed the survey online between July 2017 and March 2018.

The results of this study show that the percentages of parents who reported problematic mealtime behaviors and concerns were generally high for children of all ages, indicating that parental concerns regarding children's mealtime and eating behaviors persist throughout childhood and adolescent years. The analysis of our sample by age group suggested that picky eating may diminish over time in children with ASD. It is also possible that parents may repeatedly feed their children with their favorite foods and children eat more independently as they grow older, and therefore parents' perceived picky eating behaviors of their children may diminish even if the actual food intake may not change. The number of parents who reported that their children have no difficulty eating in any setting and eat a variety of foods increased from $6 \%$ to $36 \%$ and $46 \%$ from the early childhood age group to the mid-childhood and the adolescent age group, respectively. Many statistically significant differences indicated the highest prevalence of eating difficulties, problematic mealtime behaviors, and other issues in the early childhood group and a decreasing prevalence with age. The total mealtime behavior scale scores reiterate the higher prevalence of problems associated with mealtime behavior and food habits in younger children, as total scores were significantly higher in children ages 2-6 compared to children ages 7-11 and ages 12-17. However, it should be noted that recall bias may have impacted responses from parents of older children who were asked to recall information from several years ago. Age specific interventions may be beneficial for the eating difficulties and problematic mealtime behaviors that are specifically more prevalent in younger children with ASD.

While many reported problematic behaviors seemed to be age-dependent, others were consistently high among all three age groups. For example, prevalence of feeding concerns at ages 3 and older, exhibiting specific food preferences, and avoiding certain foods were all high for all three age groups. These findings suggest that certain problematic behaviors start early and persist until ages as old as 17 years in children with ASD. On the other hand, some (e.g., eating the same food in a repetitive manner, leaving the table frequently) were highest in the mid-childhood group, which may indicate that some habits and behaviors develop later in mid-childhood. Information on a subsample-children aged 3-6 years with ASD—was compared to information from the Provost et al. study [19]. Data from both children with ASD and typically developing children from the reference were compared to see whether our sample data was different from the reference data with and without ASD. Children aged 3-6 years with ASD in the current study showed surprising similar outcomes in most areas to those with ASD in the reference group from Provost et al. [19]. There was a significant difference in one specific early eating behavior: A lower percentage of parents in our sample reported that their children had easy feeding with strong continuous sucking in the first 3 months after birth. In addition, significantly higher percentages of participants in the current study reported that their children had eating difficulties at home and at fast food restaurants. This might be due to the different study locations and slightly different demographic characteristics between the two studies. However, further research is required to determine whether eating difficulties at home and at fast food restaurants are influenced by region. Compared with typically developing children from the reference study, significantly more parents in our study reported that their children had eating difficulties at school, regular restaurants, and picnics, indicating that many children with ASD have mealtime issues when eating out, regardless of location. 
The majority of previous studies examining problematic mealtime behaviors in children with ASD do not have any information on specific mealtime locations [2]. Possible reasons for this finding are that locations outside of the home impact parent's ability to effectively manage the behavior, or the change in routine and additional social factors outside of home mealtimes intensify problematic behavior. This might also increase parental stress and affect their quality of life in general. Food selectivity and problematic mealtime behaviors are often addressed only in clinical settings or for parents to intervene, mostly at home. Clearly, parents of children with ASD would benefit from intervention approaches that allow for community-based practice. For example, early intervention providers within the birth-3 Part C Individuals with Disabilities Education Act (IDEA) program are required to provide intervention services in the natural environment [21]. As part of this natural environment, the interventionist may decide to accompany the family to a restaurant or park picnic table to practice age-appropriate mealtime behaviors and support parents in implementing effective behavioral feeding strategies (e.g., positive reinforcement [22]). Further efforts to increase public awareness about feeding and mealtime behavioral challenges among families with ASD might be beneficial. Having restaurants and other facilities with an atmosphere that is more comfortable for children with special needs and their families might also be helpful.

The findings from this study indicate that atypical eating behaviors in infancy may be noticeable as early as in the first 3 months. A significantly higher number of parents in our study reported that they had concerns about their child's eating at 1-2 years of age, compared to parents of typically developing children in the reference study, which is consistent with the results of Provost et al.'s study. More than 70\% of parents of 3- to 6-year-old children with ASD in both our study and the reference study reported that they had feeding concerns when their children were 2-3 years old, while only $17 \%$ of parents with typically developing children reported concerns. Of the limited research on early history of feeding difficulties, parents reported signs of problematic eating/mealtime behaviors by 6 months of age [23]; however, more data is needed to determine a proper age to start screening various feeding issues. Understanding early history and atypical eating behavioral patterns may help with early diagnosis of the condition and the design of intervention techniques to improve eating habits. The birth-3 Part C program is well-positioned to screen infants and toddlers for such feeding difficulties and to develop and implement early intervention programs. Further evidence is needed to conclude whether children having early feeding difficulties before their first birthday is associated with ASD and other developmental disabilities.

The overall mealtime behavior scale indicated that our sample of children with ASD had significantly more problematic behaviors than the typically developing children in the reference study. Item-by-item analyses show several specific differences between children aged 3-6 years in our sample and typically developing children. Those behaviors were mostly related to food preference or rigidity rather than behavioral issues such as tantrums or being restless at mealtime, which were also common in typically developing children. A significantly greater number of children with ASD in our sample were considered picky eaters, require food prepared in a special way, had a problem with gagging, craved certain foods, and had favorite food textures. These features have been frequently reported as problematic among children with ASD [24,25]. Consistent with other studies $[2,10,25,26]$, the parents in our study also reported that their children did not eat a variety of foods: Only one out of 15 children aged 3 to 6 years old in our sample $(7 \%)$ ate a variety of foods, while almost $60 \%$ of typically developing children in the reference study did so.

Sensory difficulties along with behavioral rigidity and impaired social learning could likely contribute to the differences found between children with ASD and typically developing children [27]. Several studies have shown that significant sensory differences may exist between children with ASD and typically developing children, which can cause the evidenced difficulties with eating, e.g., selective eating or food refusal [28-32]. However, it is still unclear whether sensory-based therapies will improve mealtime behavior and selective eating problems [33]; therefore, further intervention 
studies examining efficacy of such strategies are warranted and large-scale research on the most effective strategies to address these difficulties (whether sensory based or behavioral) are needed.

The limitations of the current study include that we used a convenience sample and a parent-report method of data collection. It is possible that the parents who participated in this study may have had more severe mealtime behavior or nutritional concerns regarding their children. Additionally, parents were asked to recall details about their children's early feeding history. Parents of older children in particular may have had a difficult time recalling such information. In addition to the recall bias limitation, our sample has a limitation of small and unequal group sizes, with the 12-17 age group having only 11 children. More research is needed to examine further age differences in mealtime behaviors and eating habits among children and adolescents with ASD. Another limitation is that we did not collect our own control group with parents of typically developing children, but using the typically developing control from the study that used exactly the same questionnaire was beneficial. Further studies in the same regions with similar demographic characteristics would provide better matched comparisons. The results of this study are not generalizable to other settings and populations with different demographic backgrounds. Lastly, even though the instrument was previously tested for face and content validity [19] and the internal consistency reliability was high in the current study, to utilize this instrument more broadly, further studies assessing its construct validity and reliability are necessary. Despite these limitations, this is one of a few studies to measure early history of feeding difficulties and feeding environment among children with ASD. In addition, since the study participants were from across Florida, the findings of this study may inform professionals and agencies that work with children on the spectrum and their families, particularly in Florida. This is also one of few studies that included a wide range of age groups and compared outcomes by three age categories (i.e., early childhood, mid-childhood, and adolescents), making it possible to see whether common mealtime and eating problems persist until adolescence and whether there are significant differences among age groups.

As there are growing health concerns such as obesity in populations with ASD, more research is needed to investigate how the mealtime and eating behavior problems are associated with health outcomes such as obesity or diabetes, and what intervention strategies can effectively address both problematic mealtime behaviors and the health outcomes in children with ASD. In addition, it would be worth further investigating whether mealtime behaviors are directly associated with potential nutrient deficiencies.

\section{Conclusions}

The results of this study confirm previous findings that children with ASD exhibit significantly more problematic mealtime behaviors than typically developing children. Some of these problems, such as eating difficulties in various settings, may diminish with age, while others, such as avoiding certain foods, may persist through adolescence. Features of feeding issues identified in this study included difficulties in early feeding (i.e., breastfeeding), not eating a variety of foods, difficulties of eating at different locations, being a picky eater, ritualistic manners, gagging, stuffing mouth or cheeks with foods, craving certain foods, having favorite food textures, and mouthing nonfood items. Our findings with regard to age group suggest that early childhood intervention for feeding difficulties in children with ASD are warranted. Further research in adolescents with ASD and whether problematic mealtime behaviors are associated with nutritional inadequacy or other health outcomes is needed. Lastly, it might be worth exploring whether an early screening for feeding difficulties can be used as a potential criterion for ASD diagnosis.

Author Contributions: All authors made contributions to the manuscript and approved the final version of manuscript. H.L.G. was the PI of the study, designing and overseeing the study along with funding acquisition, and critically revised the manuscript. S.S. conducted the data analysis and prepared the original draft. A.W.B. conducted data collection, assisted with data management and project administration, and participated in drafting and editing the manuscript. C.R. was the project coordinator of the study, and created and administered the online 
version of the survey. K.B. is the executive director of the Center for Autism and Related Disabilities, helping with study design, recruitment, and interpreting the results. H.A. and E.S.-H. reviewed and edited the manuscript.

Funding: This work was supported by the University of South Florida Research and Innovation Internal Awards Program under Grant No. 0128126.

Acknowledgments: We thank all organizations that helped us in recruiting participants. We would also like to thank all the parents who participated in this research.

Conflicts of Interest: The authors declare no conflict of interest. The funding sponsor had no role in the design of the study; in the collection, analyses, or interpretation of data; in the writing of the manuscript, and in the decision to publish the results.

\section{References}

1. Marshall, J.; Ware, R.; Ziviani, J.; Hill, R.J.; Dodrill, P. Efficacy of interventions to improve feeding difficulties in children with autism spectrum disorders: A systematic review and meta-analysis. Child Care Health Dev. 2014, 41, 278-302. [CrossRef] [PubMed]

2. Sharp, W.G.; Berry, R.C.; McCracken, C.; Nuhu, N.N.; Marvel, E.; Saulnier, C.A.; Klin, A.; Jones, W.; Jaquess, D.L. Feeding problems and nutrient intake in children with autism spectrum disorders: A meta-analysis and comprehensive review of the literature. J. Autism Dev. Disord. 2013, 43, 2159-2173. [CrossRef] [PubMed]

3. Ranjan, S.; Nasser, J.A. Nutritional status of individuals with autism spectrum disorders: Do we know enough? Adv. Nutr. 2015, 6, 397-407. [CrossRef] [PubMed]

4. Tanner, K.; Case-Smith, J.; Nahikian-Nelms, M.; Ratliff-Schaub, K.; Spees, C.; Darragh, A.R. Behavioral and Physiological Factors Associated with Selective Eating in Children with Autism Spectrum Disorder. Am. J. Occup. Ther. 2015, 69, 6906180030p1-6906180030p8. [CrossRef] [PubMed]

5. Schreck, K.A.; Williams, K.; Smith, A.F. A comparison of eating behaviors between children with and without autism. J. Autism Dev. Disord. 2004, 34, 433-438. [CrossRef] [PubMed]

6. Bandini, L.G.; Anderson, S.E.; Curtin, C.; Cermak, S.; Evans, E.W.; Scampini, R.; Maslin, M.; Must, A. Food selectivity in children with autism spectrum disorders and typically developing children. J. Pediatr. 2010, 157, 259-264. [CrossRef] [PubMed]

7. Sharp, W.G.; Postorino, V.; McCracken, C.E.; Berry, R.C.; Criado, K.K.; Burrell, T.L.; Scahill, L. Dietary Intake, Nutrient Status, and Growth Parameters in Children with Autism Spectrum Disorder and Severe Food Selectivity: An Electronic Medical Record Review. J. Acad. Nutr. Diet. 2018, 118, 1943-1950. [CrossRef] [PubMed]

8. Johnson, C.R.; Turner, K.; Stewart, P.A.; Schmidt, B.; Shui, A.; Macklin, E.; Reynolds, A.; James, J.; Johnson, S.L.; Manning Courtney, P.; et al. Relationships Between Feeding Problems, Behavioral Characteristics and Nutritional Quality in Children with ASD. J. Autism Dev. Disord. 2014, 44, 2175-2184. [CrossRef] [PubMed]

9. Curtin, C.; Hubbard, K.; Anderson, S.E.; Mick, E.; Must, A.; Bandini, L.G. Food selectivity, mealtime behavior problems, spousal stress, and family food choices in children with and without autism spectrum disorder. J. Autism Dev. Disord. 2015, 45, 3308-3315. [CrossRef] [PubMed]

10. Marshall, J.; Hill, R.J.; Ziviani, J.; Dodrill, P. Features of feeding difficulty in children with Autism Spectrum Disorder. Int. J. Speech-Lang. Pathol. 2014, 16, 151-158. [CrossRef] [PubMed]

11. Evans, E.W.; Must, A.; Anderson, S.E.; Curtin, C.; Scampini, R.; Maslin, M.; Bandini, L. Dietary Patterns and Body Mass Index in Children with Autism and Typically Developing Children. Res. Autism Spectr. Disord. 2012, 6, 399-405. [CrossRef] [PubMed]

12. Hill, A.P.; Zuckerman, K.E.; Fombonne, E. Obesity and Autism. Pediatrics 2015, 136, 1051-1061. [CrossRef] [PubMed]

13. Zheng, Z.; Zhang, L.; Li, S.; Zhao, F.; Wang, Y.; Huang, L.; Huang, J.; Zou, R.; Qu, Y.; Mu, D. Association among obesity, overweight and autism spectrum disorder: A systematic review and meta-analysis. Sci. Rep. 2017, 7, 11697. [CrossRef] [PubMed]

14. Curtin, C.; Jojic, M.; Bandini, L.G. Obesity in children with autism spectrum disorder. Harv. Rev. Psychiatry 2014, 22, 93-103. [CrossRef] [PubMed] 
15. Tyler, C.V.; Schramm, S.C.; Karafa, M.; Tang, A.S.; Jain, A.K. Chronic disease risks in young adults with autism spectrum disorder: Forewarned is forearmed. Am. J. Intell. Dev. Disabil. 2011, 116, 371-380. [CrossRef] [PubMed]

16. Ledford, J.R.; Gast, D.L. Feeding Problems in Children with Autism Spectrum Disorders: A Review. Focus Autism Other Dev. Disabil. 2006, 21, 153-166. [CrossRef]

17. Kuschner, E.S.; Eisenberg, I.W.; Orionzi, B.; Simmons, W.K.; Kenworthy, L.; Martin, A.; Wallace, G.L. A Preliminary Study of Self-Reported Food Selectivity in Adolescents and Young Adults with Autism Spectrum Disorder. Res. Autism Spectr. Disord. 2015, 15, 53-59. [CrossRef] [PubMed]

18. Suarez, M.A.; Nelson, N.W.; Curtis, A.B. Longitudinal follow-up of factors associated with food selectivity in children with autism spectrum disorders. Autism 2014, 18, 924-932. [CrossRef] [PubMed]

19. Provost, B.; Crowe, T.K.; Osbourn, P.L.; McClain, C.; Skipper, B.J. Mealtime behaviors of preschool children: Comparison of children with autism spectrum disorder and children with typical development. Phys. Occup. Ther. Pediatr. 2010, 30, 220-233. [CrossRef] [PubMed]

20. Tavakol, M.; Dennick, R. Making sense of Cronbach's alpha. Int. J. Med. Educ. 2011, 2, 53-55. [CrossRef] [PubMed]

21. United States Department of Education Early Intervention Program for Infants and Toddlers with Disabilities. Available online: http: / www2.ed.gov/programs/osepeip/index.html (accessed on 6 August 2018).

22. Williams, K.E.; Foxx, R.M. Treating Eating Problems of children with Autism Spectrum Disorders and Developmental Disabilities; PRO-ED, Inc.: Austin, TX, USA, 2007.

23. Emond, A.; Emmett, P.; Steer, C.; Golding, J. Feeding symptoms, dietary patterns, and growth in young children with autism spectrum disorders. Pediatrics 2010, 126, e337-e342. [CrossRef] [PubMed]

24. Nadon, G.; Feldman, D.E.; Dunn, W.; Gisel, E. Association of sensory processing and eating problems in children with autism spectrum disorders. Autism Res. Treat. 2011, 2011, 541926. [CrossRef] [PubMed]

25. Odar Stough, C.; Dreyer Gillette, M.L.; Roberts, M.C.; Jorgensen, T.D.; Patton, S.R. Mealtime behaviors associated with consumption of unfamiliar foods by young children with autism spectrum disorder. Appetite 2015, 95, 324-333. [CrossRef] [PubMed]

26. Mari-Bauset, S.; Zazpe, I.; Mari-Sanchis, A.; Llopis-Gonzalez, A.; Morales-Suarez-Varela, M. Food Selectivity in Autism Spectrum Disorders: A Systematic Review. J. Child Neurol. 2014, 29, 1554-1561. [CrossRef] [PubMed]

27. Hubbard, K.L.; Anderson, S.E.; Curtin, C.; Must, A.; Bandini, L.G. A Comparison of Food Refusal Related to Characteristics of Food in Children with Autism Spectrum Disorder and Typically Developing Children. J. Acad. Nutr. Diet. 2014, 114, 1981-1987. [CrossRef] [PubMed]

28. Cermak, S.A.; Curtin, C.; Bandini, L.G. Food selectivity and sensory sensitivity in children with autism spectrum disorders. J. Am. Diet. Assoc. 2010, 110, 238-246. [CrossRef] [PubMed]

29. Ben-Sasson, A.; Hen, L.; Fluss, R.; Cermak, S.A.; Engel-Yeger, B.; Gal, E. A meta-analysis of sensory modulation symptoms in individuals with autism spectrum disorders. J. Autism Dev. Disord. 2009, 39, 1-11. [CrossRef] [PubMed]

30. Benson, J.D.; Parke, C.S.; Gannon, C.; Muñoz, D. A Retrospective Analysis of the Sequential Oral Sensory Feeding Approach in Children with Feeding Difficulties. J. Occup. Ther. Sch. Early Interven. 2013, 6, 289-300. [CrossRef]

31. Lane, A.E.; Geraghty, M.E.; Young, G.S.; Rostorfer, J.L. Problem Eating Behaviors in Autism Spectrum Disorder Are Associated with Suboptimal Daily Nutrient Intake and Taste/Smell Sensitivity. Infant Child Adolesc. Nutr. 2014, 6, 172-180. [CrossRef]

32. Chistol, L.T.; Bandini, L.G.; Must, A.; Phillips, S.; Cermak, S.A.; Curtin, C. Sensory Sensitivity and Food Selectivity in Children with Autism Spectrum Disorder. J. Autism Dev. Disord. 2018, 48, 583-591. [CrossRef] [PubMed]

33. Seiverling, L.; Anderson, K.; Rogan, C.; Alaimo, C.; Argott, P.; Panora, J. A Comparison of a Behavioral Feeding Intervention with and without Pre-meal Sensory Integration Therapy. J. Autism Dev. Disord. 2018, 48, 3344-3353. [CrossRef] [PubMed]

(C) 2018 by the authors. Licensee MDPI, Basel, Switzerland. This article is an open access article distributed under the terms and conditions of the Creative Commons Attribution (CC BY) license (http://creativecommons.org/licenses/by/4.0/). 